\title{
Estresse Ocupacional: Uma análise sobre causas, consequências e prevenções em uma clínica médica na cidade de Juazeiro do Norte-CE
}

\author{
Ana Lecia Pereira Alves ${ }^{1}$; Márcia Maria Leite Lima²
}

Resumo: Uma boa saúde ocupacional é algo importante dentro de qualquer empresa, seja qual for o seu propósito, toda empresa deve conter profissionais qualificados para a fomentação das suas atividades organizacionais, onde estas por vez devem estar alinhadas a pessoas capacitadas que se preocupem com o bem-estar organizacional, quanto com a saúde ocupacional dos colaboradores. Esse estudo tem por objetivo geral, estudar quais os fatores influenciadores do estresse ocupacional em uma clínica médica na cidade de Juazeiro do Norte- CE. Seguido dos objetivos específicos que é analisar se a comunicação é um fator influenciador, verificar se a cultura organizacional favorece a desmotivação do indivíduo dentro da organização, identificar se a qualidade de vida dentro da organização é satisfatória e investigar os danos que o estresse ocupacional pode ocasionar a saúde do trabalhador dentro da organização. Para obter os resultados foi realizada uma pesquisa pelos métodos mistos Quantiqualitativo, descritiva. Através do processo metodológico foi possível identificar os resultados que não foram satisfatórios aos objetivos, pois na pesquisa obteve-se que os agentes estressores são devidamente encarados e controlados se tornando assim fatores de crescimento ao colaborador.

Palavras-Chave: Saúde Ocupacional. Bem-Estar. Estresse.

\section{Occupational Stress: An analysis of causes, consequences and preventions in a medical clinic in the city of Juazeiro do Norte, State of Ceará}

\begin{abstract}
A good occupational health is important within any company, whatever your purpose, every company must contain qualified professionals to the fomentation of their organizational activities, where these at a time must be aligned to people able to worry about organizational well-being, as well as the occupational health of the employees. This study aims to study what General factors influencing occupational stress in a medical clinic in the town of Juazeiro do Norte-CE. Followed by the specific objectives which is to analyze if the communication is an influential factor, verify that the organizational culture favors the discouragement of the individual within the Organization, identify whether the quality of life within the organization is satisfactory and investigate the damage that the occupational stress can lead to worker's health within the organization. To get the results a survey was carried out by mixed quantitative and qualitative methods, descriptive. Through the methodological process it was possible to identify the results were not satisfactory, because in research objectives was that agents stressors are properly addressed and controlled becoming so growth factors to collaborator.
\end{abstract}

Keywords: Occupational Health. Wellness. Stress.

\footnotetext{
${ }^{1}$ Graduanda do curso de Administração do Centro Universitário Doutor Leão Sampaio/Unileão. Email: Lecia.alves93@gmail.com;

${ }^{2}$ Professora orientando do Centro Universitário Doutor Leão Sampaio/Unileão especialista em Gestão de Estratégia e Pessoas. E-mail: marcialeite@leaosampaio.edu.br.
} 


\section{Introdução}

Em um ambiente altamente competitivo as organizações nos últimos anos intensificam o seu modo de gerir, e com isso as empresas passam a intensificar sobrecargas e cobranças para estimular o desempenho a fim de que rapidamente o objetivo seja alcançado com uma melhor qualidade.

A gestão de pessoas ou recursos humanos relaciona-se como um "Contrato psicológico" sendo assim denominada através da nova gestão ou até melhor falando, da nova forma de gerenciar colaboradores, este novo modelo surgi de um ambiente mais competitivo e que este, deve estar sempre alinhado ao desenvolvimento do mercado e ocupacional. As empresas com o decorrer do tempo passaram por diversas mudanças e entre elas, o que vem a ser uma real diferença é a relação interpessoal de empregado com empregador, nos primórdios da gestão os colaboradores eram vistos apenas como empregados, cujo eram pagos apenas para fazer sua função especifica, sem nenhuma correlação com a gestão (DUTRA, 2016).

Perante esse cenário, observa-se que a pressão por produtividade e metas se tornou cotidiana, favorecendo ao adoecimento, podendo vir a ocasionar o estresse.

Dessa maneira, o objetivo da pesquisa é estudar quais os fatores influenciadores do estresse ocupacional em uma clínica médica na cidade de Juazeiro do Norte- CE.

Dispondo como meta para que o objetivo principal seja alcançado, os objetivos específicos constituem-se em, analisar se a comunicação é um fator influenciador, verificar se a cultura organizacional favorece a desmotivação do indivíduo dentro da organização, identificar se a qualidade de vida dentro da organização é satisfatória e investigar os danos que o estresse ocupacional pode ocasionar a saúde do trabalhador dentro da organização.

No convívio do dia a dia ou dentro de organizações é comum ouvir relatos de pessoas que se dizem estar estressadas e que na maioria das vezes não é dedicado a devida atenção e como habitual acontece julgamentos, devido estar intimamente ligados as crenças de cada indivíduo e é entendido conforme suas próprias experiências e subjetividade prejudicando emocionalmente a situação do mesmo.

O Estresse ocupacional é um fator causador de doenças que afetam o desempenho profissional e pessoal diante de pressões externas e assim sendo estímulos de influências 
negativas a saúde do colaborador e para a própria organização economicamente (FRANÇA, 2008).

No contexto atual, o estilo de vida das pessoas é de muita movimentação, muitas pessoas trabalham demais, não tem tempo de se cuidar, de cuidar da saúde física e mental. Diante desse quesito o presente estudo objetivou-se no problema surgindo a seguinte pergunta: Por que o estresse implica de forma negativa no desenvolvimento de atividades profissionais gerando desmotivação e baixa produtividade em situações desempenhadas dentro da organização? Nesta direção buscou estudar hipóteses que podem ser fatores contribuintes para o estresse organizacional, sendo elas: A cultura organizacional pode ser influenciadora de causas e efeitos do estresse nos indivíduos, o estresse pode reduzir a produtividade do indivíduo dentro da organização, insatisfação com a vida e a rotina de trabalho podem gerar baixa produtividade, a sobrecarga de trabalho é um fator influenciador para o estresse do indivíduo.

Esse trabalho tem sua justificativa apoiada pela proveniente inquietação do contato direto e diário da rotina de colegas de trabalho, dentro de uma clínica médica na cidade de Juazeiro do Norte-CE, podendo assim compreender o motivo da disparidade de atividades por eles desempenhadas.

No entanto, as empresas têm como desafio promover benefícios que atendam às necessidades dos seus colaboradores, pois sendo importante reorganizar o ambiente de trabalho para assim conceder bem-estar, melhor controle sobre emoções que venham causar desgastes, e capacidade de assumir atitudes mais positiva e novas perspectivas de vida assim facilitando o desempenho de atividades sem risco para a saúde.

Esse estudo trará ao pesquisador conhecimentos e saberes em relação as causas e efeitos do estresse ocupacional, podendo contribuir de forma significativa para o crescimento profissional. Bem como, atuar como fonte de conhecimento para a sociedade empresarial sobre os riscos advindos do estresse podendo vir a proporcionar problemas na saúde física e psíquica. 


\section{Referencial Teórico}

\section{Ambiente Organizacional}

O ambiente de trabalho é caracterizado pela pureza do espirito de cooperação de diversos indivíduos que tem objetivos em comum através da coordenação de seus esforços, e também pelas constantes pressões ao alcance em atingir metas e cumprir normas e valores (MORGAN, 2002).

As organizações só atingem seus objetivos pelo alto desempenho e visão de crescimento das pessoas, e por conta da comunicação e criação do sistema do comportamento da organizacional. Pois quando não alcançado essa finalidade abre espaço para a ansiedade, que é a base para doenças e desorganizações (LACOMBE, 2005).

Entretanto, as organizações são permeadas de decisões e ações e a perspectiva comportamental concebe a organização como um sistema complexo de decisões, diante da perspectiva comportamental em todas as áreas de atividades, todas as pessoas que fazem a organização e em níveis hierárquicos estão continuamente tomando decisões relacionadas ou não com seu trabalho (ROBBINS, 2009).

E com isso, vem a noção das necessidades humanas, elas desempenham um papel de grande importância na vida do indivíduo estabelecidas em níveis hierárquicos, favorecendo ao estudo da motivação do mesmo dentro da organização, pois as pessoas estão sempre em processo de desenvolvimento continuo sendo assim, os estímulos interiores são chamados de necessidades, que são fatores motivacionais do comportamento humano (MAXIMIANO, 2011).

Para uma melhor compreensão ao assunto abordado, a figura abaixo apresenta a hierarquia das necessidades humanas desempenhando o papel de esclarecimento dos tipos de necessidades dos indivíduos: 
Figura 1: Hierarquia das Necessidades Humanas

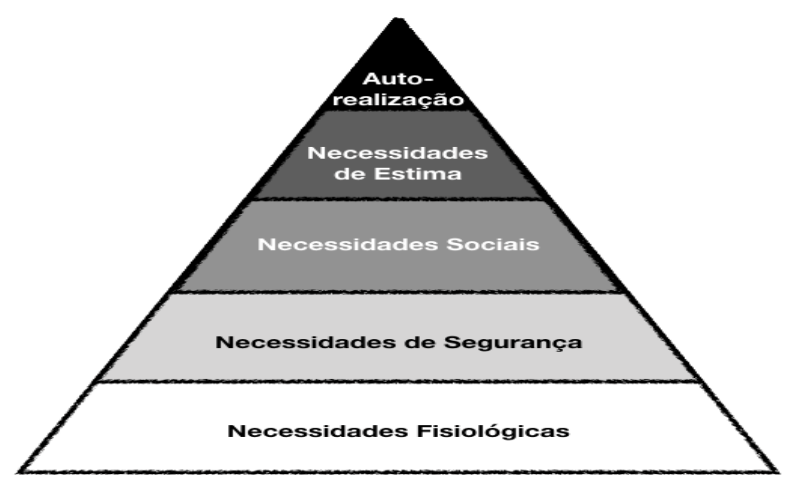

Fonte: MAXIMIANO, (2011)

Pois o ambiente de trabalho desencadeia emoções. A qualidade do trabalho decorre em grande parte da qualidade dos conhecimentos estabelecidos, conflitos no ambiente organizacional geram reações emocionais que podem levar do absenteísmo ao adoecimento no trabalho, e se as relações forem positivas oferecem equilíbrio emocional e sentido de vida (ZANELLI; BORGES-ANDRADE; BASTOS, 2014).

\section{Estresse}

O estresse é reação que o organismo do indivíduo tem diante de pressões internas e externas, podendo vir a acontecer em situações diárias ou eventualmente produzindo hormônios vindo a surgir irritações, frustação, preocupação, sensações de desconforto mais outras emoções negativas sendo intensas ou continuas (BARROS; FUNKE; LOURENÇO, 2017).

Diante de algumas insatisfações oriundas do trabalho pode levar ao absenteísmo, e trazer várias doenças, como: problemas no coração, estresse, pressão e ulceras, devido à pressão do ambiente de trabalho podendo assim acarretar elevados gastos com assistência medica nas empresas (FERREIRA,2017). 
Pode-se citar como o maior vilão atual responsável por grandes desgraças pessoais e de saúde é o stress. Pois e de responsabilidade dele grandes acontecimentos desdá ulcera do executivo ao baixo rendimento de um atleta, trazendo como consequência a diminuição da qualidade de vida (FRANÇA; RODRIGUES, 2013).

\section{Estresse no Ambiente de Trabalho}

Muitas das causas de desgaste que são encontradas no ambiente de trabalho, as origens são constatadas em seis pontos de desequilíbrio sendo eles: renumeração insuficiente, ausência de equidade, excesso de trabalho, renumeração, colapso da união e valores conflitantes (ZANELLI, 2010).

Verificando que o indivíduo tem diferentes limites de resistência ao estresse ele acontece por diversos fatores, naturezas e causas dentro das organizações (FIORELLI, 2018).

A saúde organizacional é algo que vem sendo estudado e analisado nos últimos anos de gestão, a questão de bem-estar organizacional, não pertence mais apenas aos colaboradores e sim à organização e a todos que compõe o corpo gerencial e organizacional, foi visto que um colaborador estando doente este não dispõe de toda a sua capacidade mediante o desenvolver da sua função (BERGAMINE, 2018).

As atividades desenvolvidas em contextos de risco são aspectos característicos de uma qualidade de vida no trabalho desta forma torna-se necessário a real compreensão do que o estresse pode favorecer ao mal estar ocupacional, A gestão deve estar atenta e preocupada com a saúde não só física mais a boa saúde mental da empresa sendo ela, não apenas a parte administrativa mais também o chão de fábrica, onde este deve estar assegurado e atrelado a segurança no trabalho, o que a Qualidade de vida no trabalho (QVT) abrange com seus aspectos e conhecimentos é a principal relação da gerencia com os colaboradores no envolvimento de preocupação e atenção para que sua produção seja algo crescente (LIMONGI-FRANÇA, 2012).

O estresse é a resposta do organismo mediante situações que o obrigue a lidar com comportamento no seu limite. Todas as situações vivenciadas pelos trabalhadores, pode levar lós a apresentar os seguintes sintomas: insegurança na tomada de decisões, consumos exagerados provenientes a ocasionar problemas digestivos, tensão muscular, sendo assim 
ocasionando problemas na saúde física e/ou emocional com alterações de conduta no trabalho e em casa (COUTINHO; SANTOS, 2010).

\section{Consequências do Estresse}

O estresse ocupacional pode desencadear a síndrome psicológica no trabalho, chamada doença de burnout, que traz consequência ao indivíduo gerando a (ansiedade, depressão, medo, raiva ou irritabilidade) que são fenômenos estudados por base da fisiopatologia que constatam problemas a saúde mental, contribuindo para o absenteísmo, conflitos entre colegas e um ruim desempenho no local de trabalho (ROSSI, 2007).

O sofrimento do indivíduo traz implicações ao desempenho e ao estado de saúde, esse sofrimento acontece pelos advindos sentimentos de disfunções provocados por vários aspectos sendo eles (inutilidade, indignidade e desqualificação), e não atingindo somente o indivíduo, mas a organização em que ele se encontra como um todo. A vivencia depressiva é dominada pelo cansaço que procede dos sacrifícios psicosensoriais, existindo diversos aspectos ligado ao cansaço como: fadiga, frustação, angustia, insatisfação, medo e ansiedade (SILVA, 2000).

Uma das soluções para o problema de desgaste que afeta o indivíduo, familiares quanto empresa são programas de Qualidade de vida no trabalho (QVT), pois assim ganha o colaborador e empesa, pois, esse problema os tornam incapacitados de superar complicações que se originam no trabalho (ALVES, 2011).

\section{Saúde Ocupacional}

A alguns tempos atrás, os trabalhadores eram acostumados a encarar o risco de acidente de trabalho como se fizesse parte da rotina diária e do processo produtivo. Com o passar dos anos a visão foi se modificando e hoje o trabalhador e um aliado da segurança no trabalho e não mais aceita exercer funções que os coloquem em risco, sem qualidade de vida, estando sempre atento as cobranças e sugestões benéficas ao ambiente de trabalho (CHIRMICI; OLIVEIRA, 2016).

91 Id on Line Rev. Mult. Psic. V.12, N. 42, Supl. 1, p. 85-108, 2018 - ISSN 1981-1179 Edição eletrônica em http://idonline.emnuvens.com.br/id 
Sendo de grande importância salientar que o trabalho não é somente uma fonte de bemestar, também está associado ao mal-estar ocupacional que é composto por adversos afeitos das condições profissionais, que tem como causa e consequência o estresse profissional, causando, esgotamento, depressão, ansiedade, e insatisfação que pode se manifestar de diversas formas e são agrupadas em sintomas físicos, cognitivos, emocionais e comportamentais (SIQUEIRA, 2014).

E sendo as organizações as principais influenciadoras sobre o estado de saúde mental e emocional dos indivíduos que nelas convivem. O clima organizacional gera manifestações comportamentais inadequadas e inadaptadas, que em muitas das vezes atuam como obstáculos, podendo criar ao invés alternativas que venha para benefícios tanto para o colaborador quanto para a empresa em si (KANAANE, 2012).

O esgotamento físico e emocional é um processo progressivo ao estresse, que foi constatado visivelmente por condições do trabalho que abala o indivíduo em qualquer ambiente organizacional evidenciando a dimensão psicossocial e favorecendo no processo de adoecimento (ZANELLI, 2010).

\section{Riscos Ocupacionais}

Os riscos ocupacionais são riscos provenientes das atividades laborais, ou seja, de como é feita e gerenciada as atividades desenvolvidas nas empresas se estas trazem risco ao não para a organização. Os riscos provenientes das atividades laborais são detectados a partir das demais caracterizações: riscos de acidentes, riscos químicos, riscos físicos, riscos biológicos, riscos ergonômicos. (BARSANO E BARBOSA, 2014).

Á vista disso, tonar-se preciso a formatação da gestão de risco dentro da organização, pois o gestor deve estar sempre atento a qualquer atitude que venha a se desenvolver os riscos na sua empresa podendo ser ocupacional ou gerencial mencionados a seguir no quadro 1 : 
Quadro 1: Riscos ocupacionais

\begin{tabular}{|c|l|}
\hline Risco de acidentes & $\begin{array}{l}\text { São todos os fatores que colocam os colaboradores em risco, sejam eles de } \\
\text { físicos ou morais. Provem das atividades por eles exercidas, com correlação do } \\
\text { seu ambiente de trabalho. }\end{array}$ \\
\hline Riscos químicos & $\begin{array}{l}\text { São desenvolvidos através contato com substâncias compostos químicos e } \\
\text { solventes que venham a intervir na saúde ocupacional, penetração no } \\
\text { organismo, através deste pode haver vários meios de doenças infecciosas, } \\
\text { contaminantes ou até mesmo um câncer. }\end{array}$ \\
\hline Riscos físicos & $\begin{array}{l}\text { São inerentes e providos de diversas formas, adquiridos pelo ambiente externo } \\
\text { e interno organizacionalmente, tais como ruídos, calor, umidades, vibrações, } \\
\text { pressões anormais e radiações }\end{array}$ \\
\hline Riscos biológicos & $\begin{array}{l}\text { Provenientes da ação de fungos, parasitas, germes, vírus e entre outros. Os } \\
\text { riscos biológicos estão envolvidos onde estes agentes biológicos antes citados } \\
\text { estão inseridos, provocando assim riscos inerentes a sua composição e } \\
\text { correlação em algumas funções. }\end{array}$ \\
\hline Riscos ergonômicos & $\begin{array}{l}\text { Riscos ocupacionais que comprometem a saúde física e psíquica do } \\
\text { colaborador, muitas das vezes sem que sejam percebidos, pois são } \\
\text { desenvolvidos através da falta de postura, ritmo de trabalho, maquinas } \\
\text { utilizadas, sendo estas que desenvolvem de certa forma alguma deficiência ou } \\
\text { lesão, são também as doenças conhecidas como lesões de esforço repetitivos e } \\
\text { podem ser adquiridas de outras formas sejam elas da percepção físicas quanto } \\
\text { psicológicas, onde um colaborador pode estar passando por algo familiar, que } \\
\text { venha interferir na sua função colaborativa, ou seja, é também desenvolvida } \\
\text { pela função psicológica do colaborador. }\end{array}$ \\
\hline
\end{tabular}

Fonte: Adaptado de BARSANO e BARBOSA, 2014.

Desta forma, a gestão de riscos avalia as incertezas da melhor forma para a organização na tomada de decisões, melhorando a afetividade, performance e relacionamento da gestão com seus colaboradores, utilizando um conjunto de técnicas que visa minimizar os efeitos dos danos acidentais direcionando o tratamento aos riscos que possam causar danos ao projeto, às pessoas, ao meio ambiente e a imagem da empresa.

\section{Metodologia da Pesquisa}

A pesquisa se sucedeu a partir de estudos bibliográficos, que é realizada com base em conteúdos já validados, pois se faz necessário um embasamento teórico para consolidação dos resultados esperados, (GIL, 2010). 
Entretanto, é de cunho descritiva, onde uma das suas características é a coleta de dados e levantamentos psicossociais desenvolvidas na ciência humana e social, que são estudados fenômenos físicos e humanos, que são observados e registrados os fatos (ANDRADE, 2010).

Devido à natureza subjetiva, é por meio do método qualitativo onde são utilizadas habilidades e técnicas que são explorados de maneira proveitosa os conteúdos postulados ao entrevistado, no qual seus aspectos é percepção e motivação do público entrevistado, e investigação de valores e atitudes afim de entende-los com maior complexidade (GONÇALVES; MEIRELLES, 2004).

A pesquisa foi executada em uma Clínica médica na cidade de Juazeiro do Norte - CE, assim sendo aplicado um roteiro de entrevista estruturado composto por 13 questões, vindo a ser entrevistados o total de 20 atendentes de clínica médica de diferentes idades e ambos os sexos e assim ocorreu a análise do discurso através dos conteúdos estudados sendo eles bibliográficos para melhor obtenção de resultados.

A população da pesquisa foram os colaboradores de uma clínica médica, onde serão adquiridos conhecimentos específicos através de entrevistas semiestruturadas, com questões em formato de tópicos, para uma melhor conversa e diálogo entre as partes, de um modo que não possa haver algo a ser considerado constrangedor para o entrevistado.

Como critério de inclusão foi visto aqueles por vontade própria e curiosidade desejaram participar da pesquisa, a exclusão dos demais critérios se dado através da não participação do meio a ser pesquisado e os colaboradores que estiverem em períodos de férias e de licenças médicas.

Foi realizada entrevista aos colaboradores, com intuito de obter informações relevantes que venham a instruir o objetivo do estudo, com foco nisto as análises dos resultados esperados foram consideradas através do levantamento de informações do tema em questão de forma qualitativa.

A proposta metodológica segue uma abordagem de "Métodos Mistos" que na visão de Creswell (2010) é aquela que compõe combinações (Quanti - Qualitativa). Este mesmo autor, afirma que a pesquisa de métodos mistos "é uma abordagem de investigação que combina ou associa as formas qualitativa e quantitativa". Como são duas abordagens com características antagônicas, elas se combinam de forma que uma prevalecerá sobre a outra ao mesmo tempo em que podem se complementar na apresentação de resultados. 
Para a análises de resultados, foi realizada a transcrição de todo conteúdo obtido pelos questionários aplicados aos colaboradores e posteriormente a confrontação destes resultados com a fundamentação bibliográfica apresentada pelos teóricos citados neste artigo.

\section{Análise e Discussão dos Resultados}

Para uma melhor demonstração dos resultados deste estudo, os dados obtidos inicialmente serão apresentados em representação gráfica por abordagem metodológica quantitativa. Posteriormente serão descritos textualmente para que possa ser mensurado a abordagem metodológica qualitativa.

\section{Procedimentos}

Inicialmente foi realizada uma reunião com todos os colaboradores dos setores, para Oportunizar informações acerca do objetivo da pesquisa. Nessa apresentação houve breve exposição sobre o que é o estresse, e mais especificamente, o que é o estresse ocupacional, além de como ele pode influenciar nas relações de trabalho e na saúde do trabalhador.

A empresa estudada tem uma população de 85 colaboradores a amostra foi realizada com 20 colaboradores no período de 27/09/2018. A clínica se caracteriza por oferecer: consultas médicas e exames laboratoriais avulsos por preços módicos, profissionais qualificados, atendimento e serviços com qualidade, estrutura física adequada e agendamento rápido. A Clínica realiza, além de constantes investimentos em tecnologias, o treinamento contínuo de sua equipe com o objetivo de cumprir com os resultados esperados por todos os seus clientes, internos e externos, através de um processo contínuo de aperfeiçoamento humano, técnico e de qualidade na área da saúde.

Nos programas de aprendizagem, a empresa oferece a possibilidade de uma educação profissionalizante para o jovem menor de 18 anos que trabalha como aprendiz, na empresa. A 
remuneração, por tratar-se de um aprendiz, é menor do que a de um funcionário comum e é baseada no salário mínimo/hora. Ambos ganham nesta troca: este é o princípio.

A humanização do atendimento, a diversificação e a qualidade são as bases da atuação da empresa e fazem parte de sua origem. A instituição conta com mais de 20 especialidades médicas e clínica geral, além de exames laboratoriais, complementares, específicos, radiológicos e computadorizados.

Gráfico 01: Cruzamento Faixa etária e Escolaridade

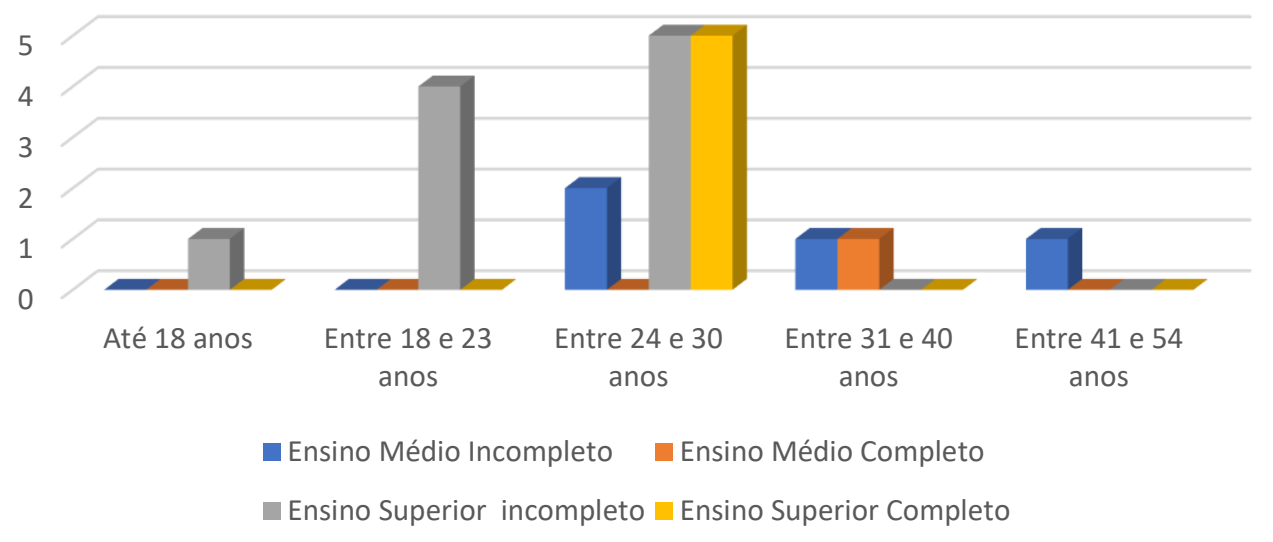

Fonte: Dados da Pesquisa 2018.

É possível perceber que os trabalhadores se distribuem entre as faixas etárias a partir 18 anos até 54 anos ou mais. Observa-se, portanto, que há uma maior predominância na faixa etária de 24 a 30 anos com escolaridade de Ensino superior completo e incompleto. Os resultados do gráfico 01, aponta aspectos de empatia em relação a idade e a escolaridade, observou- se que o nível elevado com relação a escolaridade foi com o ensino superior completo e incompleto, pois podem ser entendidos em função das oportunidades oferecidas pela vida acadêmica pois este cria um vínculo de oportunidade diversas e desenvolvimento profissional. E enquanto a faixa etária que se sobressai entre 24 e 30 anos que estes já chamados de "adultos", já tem alcançado a maturação cognitiva e emocional. 
Gráfico 02: Cruzamento perspectivas de crescimento de acordo com a faixa etária

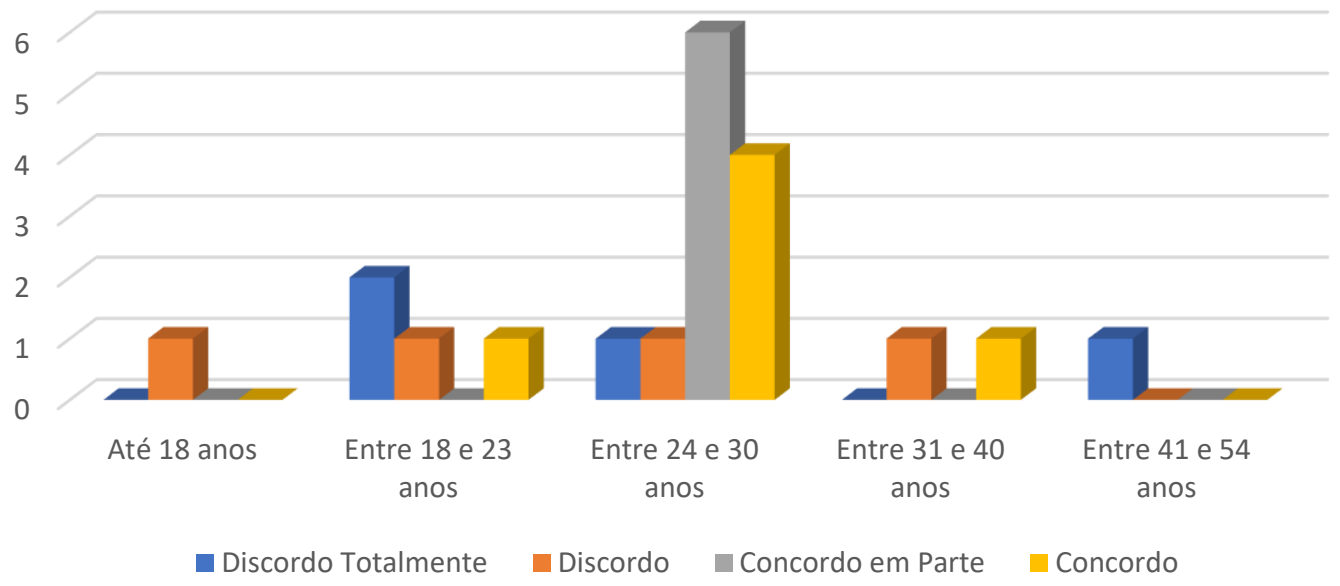

Fonte: Dados da Pesquisa 2018.

Após analisar os dados obtidos, no gráfico 02 acima, observa-se um certo índice de perspectiva de crescimento profissional entre a faixa etária de 24 a 30 anos. Isso significa para as participantes da pesquisa, um resultado benéfico, pois segundo Lacombe (2005) as organizações só atingem seus objetivos pelo alto desempenho e visão de crescimento das pessoas, e por conta da comunicação e criação do sistema do comportamento da organizacional. Pois quando não alcançado essa finalidade abre espaço para a ansiedade, que é a base para doenças e desorganizações.

Gráfico 03: Cruzamento perspectivas de crescimento de acordo com a escolaridade

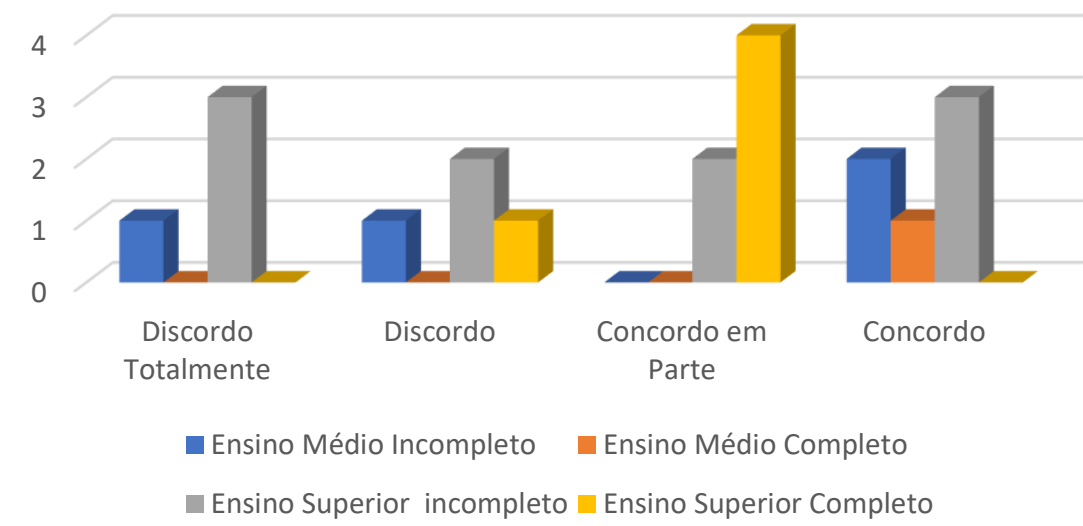

Fonte: Dados da Pesquisa 2018. 
Em síntese, o gráfico 03, mostra uma variedade em relação perspectiva de crescimento profissional de acordo com a escolaridade que se sobressai o ensino superior completo com a resposta "concordo em parte" e ensino superior incompleto com a resposta "concordo". Diante disso e perceptível que na empresa, os colaboradores que são graduados têm uma maior expectativa de crescimento em relação aos que ainda estão a concluir a graduação, pois é evidente que pessoas que tem uma maior aquisição de conhecimento, tende a ter uma expectativa de vida maior.

Gráfico 04: Relação de sobrecarga de trabalho com mau humor

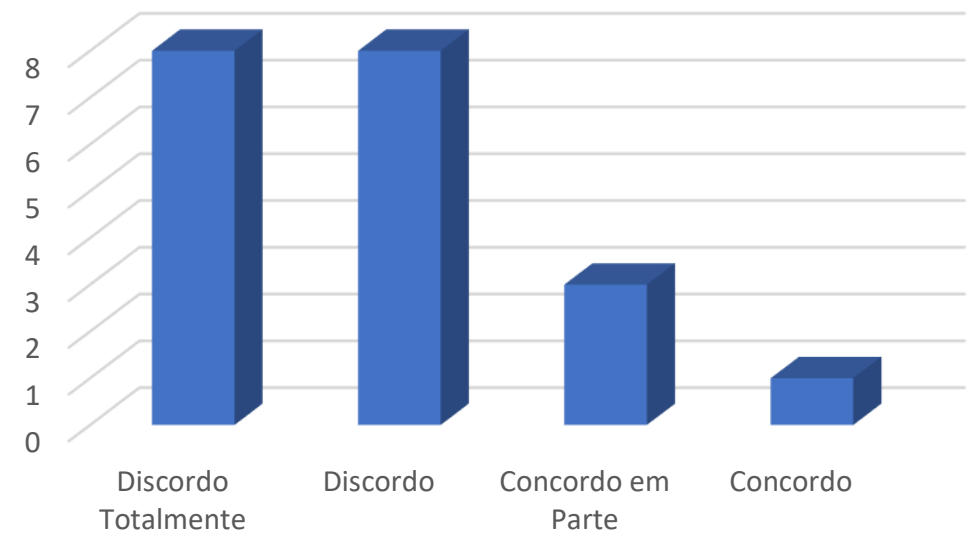

Fonte: Dados da Pesquisa 2018.

Com relação ao mau humor por trabalhar muitas horas em seguidas a maior parte dos respondentes declararam que não influencia no sentimento de estresse tendo como alto índice de respostas "discordo totalmente" e "discordo", pois segundo Morgan (2002) o ambiente de trabalho é caracterizado pela pureza do espirito de cooperação de diversos indivíduos que tem objetivos em comum através da coordenação de seus esforços, e também pelas constantes pressões ao alcance em atingir metas e cumprir normas e valores. 
Gráfico 05: Fico irritado por ser pouco valorizado por meus superiores

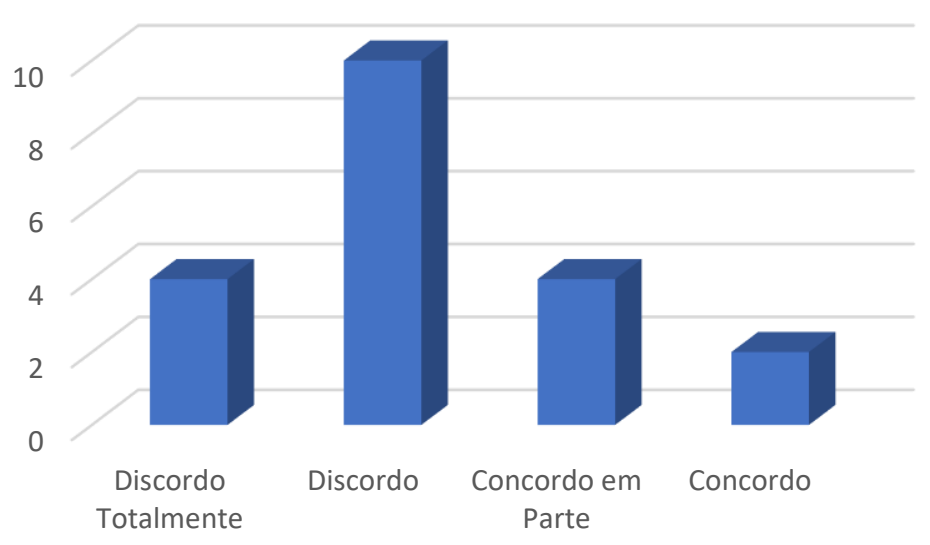

Fonte: Dados da Pesquisa 2018.

Diante da análise no gráfico 05, é perceptível que a irritabilidade por ser pouco valorizado no ambiente de trabalho não influencia no nível de estresse dos colaboradores como apresenta no gráfico 05, sendo assim Dutra (2016) relata que as empresas com o decorrer do tempo passaram por diversas mudanças e entre elas, o que vem a ser uma real diferença é a relação interpessoal de empregado com empregador, nos primórdios da gestão os colaboradores eram vistos apenas como empregados, cujo eram pagos apenas para fazer sua função especifica, sem nenhuma correlação com a gestão.

Gráfico 06: As poucas perspectivas de crescimento na carreira dentro da empresa têm me deixado angustiado

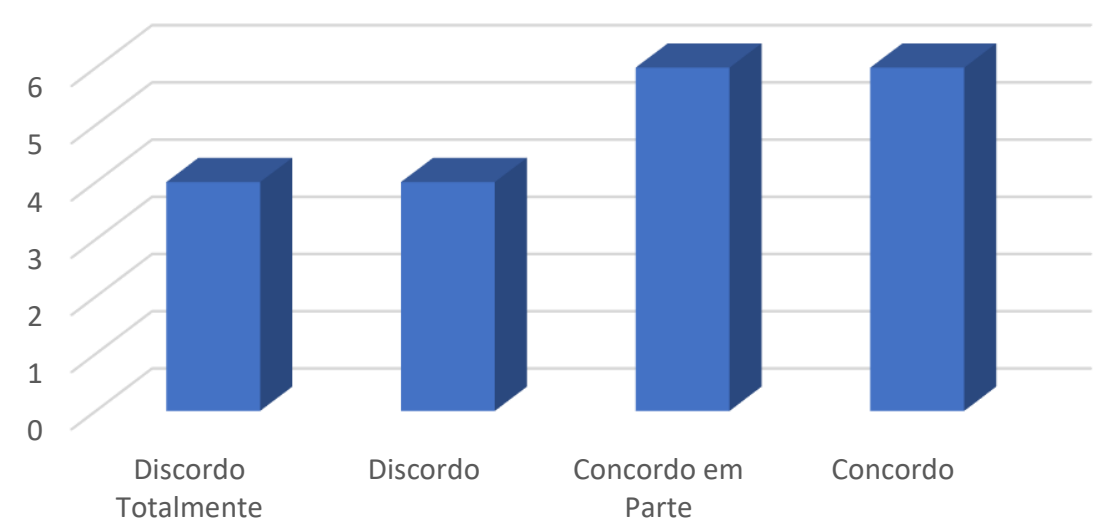

Fonte: Dados da Pesquisa 2018. 
Ao analisar a escala do gráfico 06, a dimensão da perspectiva de crescimento na carreira dentro da empresa, em relação ao deixar o colaborador angustiado, é notório que os resultados apresentam um elevado nível de afirmativas favorecendo ao estresse, pois segundo Kanaane (2012) as organizações são as principais influenciadoras sobre o estado de saúde mental e emocional dos indivíduos que nelas convivem, pois, o clima organizacional gera manifestações comportamentais inadequadas e inadaptadas.

Gráfico 07: A falta de compreensão sobre os quais são as minhas responsabilidades neste trabalho tem me causado irritação

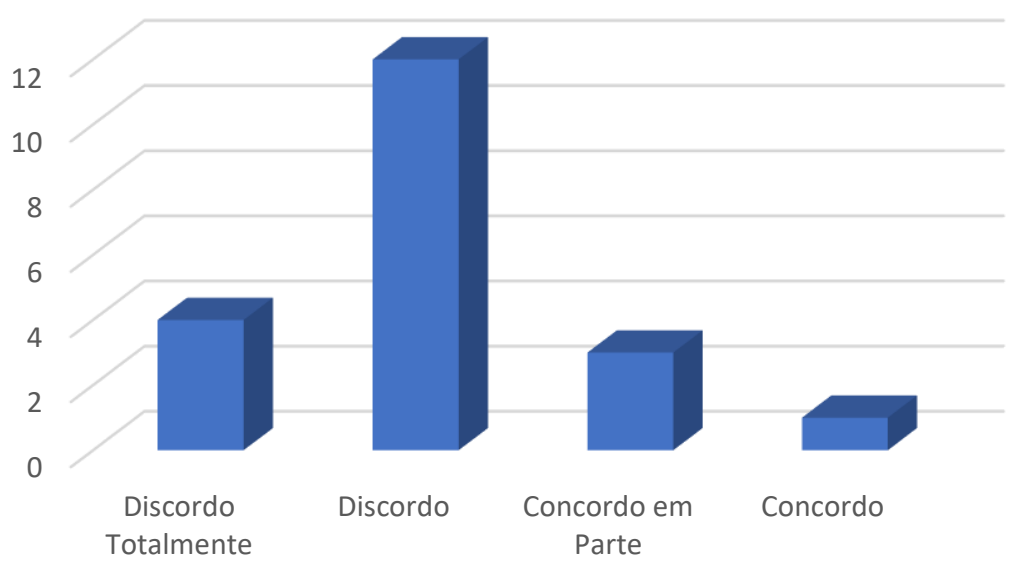

Fonte: Dados da Pesquisa 2018.

Com base no gráfico 07, é possível identificar que a respeito à falta de compreensão as quais são as responsabilidades dos colaboradores no trabalho, a maior parte "discordaram" que não vem a causar irritabilidade pois, segundo Zanelli; Borges-Andrade; Bastos (2014) a qualidade do trabalho decorre em grande parte da qualidade dos conhecimentos estabelecidos, conflitos no ambiente organizacional geram reações emocionais que podem levar do absenteísmo ao adoecimento no trabalho, e se as relações forem positivas oferecem equilíbrio emocional e sentido de vida. 
Gráfico 08: A falta de comunicação causa irritação

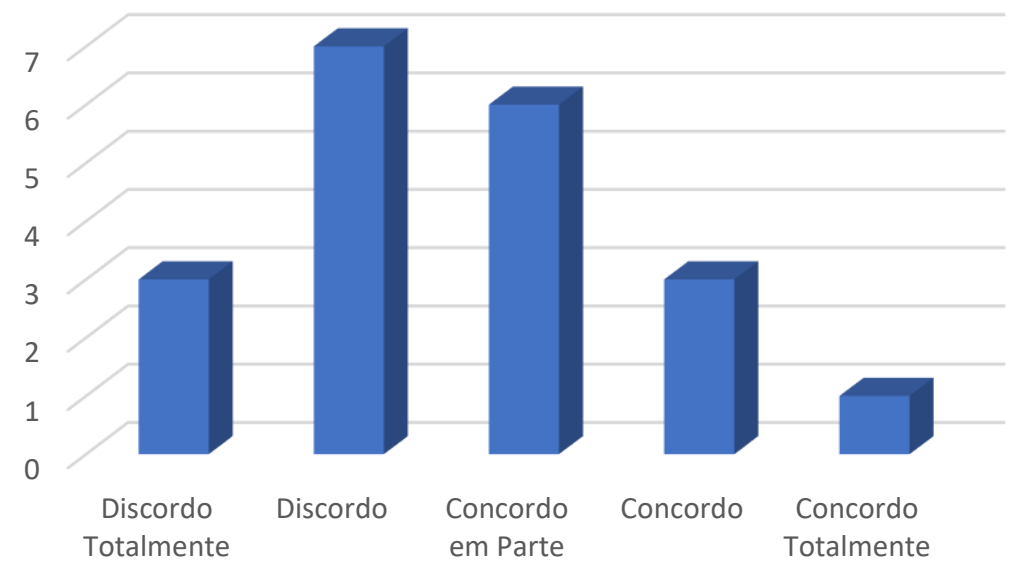

Fonte: Dados da Pesquisa 2018.

A partir da escala das medias auferidas no gráfico 08, é possível identificar duas maiores variações a respeito à falta de comunicação se gera irritabilidade entre os colaboradores, sendo que em alta escala a maior parte "discordaram" e ficando em segundo mais votado os que "concordaram em parte", pois como mostra a escala os resultados revelaram um equilíbrio entre partes pois, segundo Fiorelli (2018) o indivíduo tem diferentes limites de resistência ao estresse ele acontece por diversos fatores, naturezas e causas dentro das organizações.

Gráfico 09: Relação de incomodo por ter que realizar tarefas além da capacidade

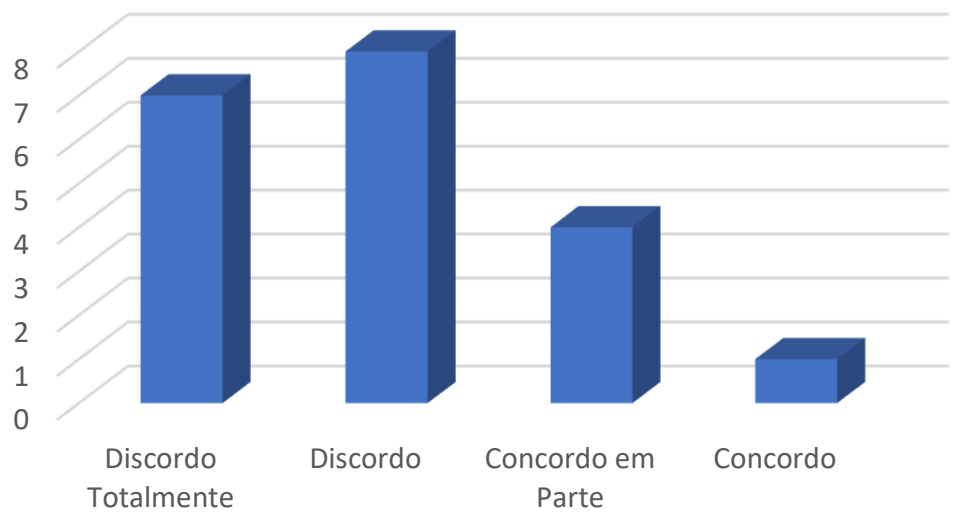

Fonte: Dados da Pesquisa 2018. 
Com relação as características do trabalho, identificou-se no gráfico 09, o nível de satisfação enquanto a realização de tarefas que estão além da capacidade do colaborador que segundo os respondentes a maior parte "discordaram", pois, entendendo assim que não seja um estressor organizacional, que segundo Bergamine (2018) a saúde organizacional é algo que vem sendo estudado e analisado nos últimos anos de gestão, a questão de bem-estar organizacional, não pertence mais apenas aos colaboradores e sim à organização e a todos que compõe o corpo gerencial e organizacional, foi visto que um colaborador estando doente este não dispõe de toda a sua capacidade mediante o desenvolver da sua função.

Gráfico 10: A falta de informação sobre minhas tarefas me incomoda

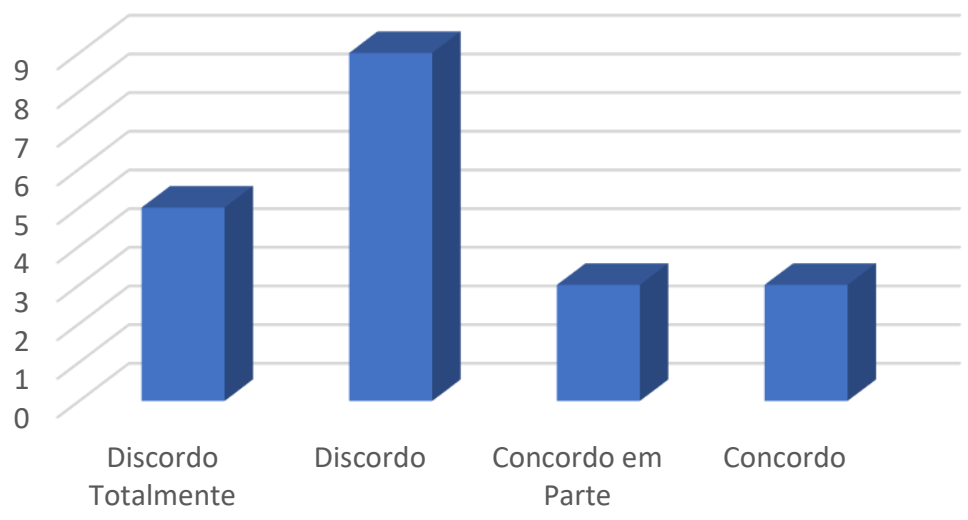

Fonte: Dados da Pesquisa 2018.

A análise do gráfico 10, permite a identificação de maior escala "discordo" em relação a falta de informação na qual são as tarefas dos colaboradores, o que evidencia que na empresa apresenta que a comunicação entre partes é favorável tendo uma boa relação. O resultado mostra-se satisfatório, pois os indivíduos desempenham suas tarefas de forma correta, com foco no que estão realizando. 
Gráfico 11: Fico de mau humor por me sentir isolado no trabalho

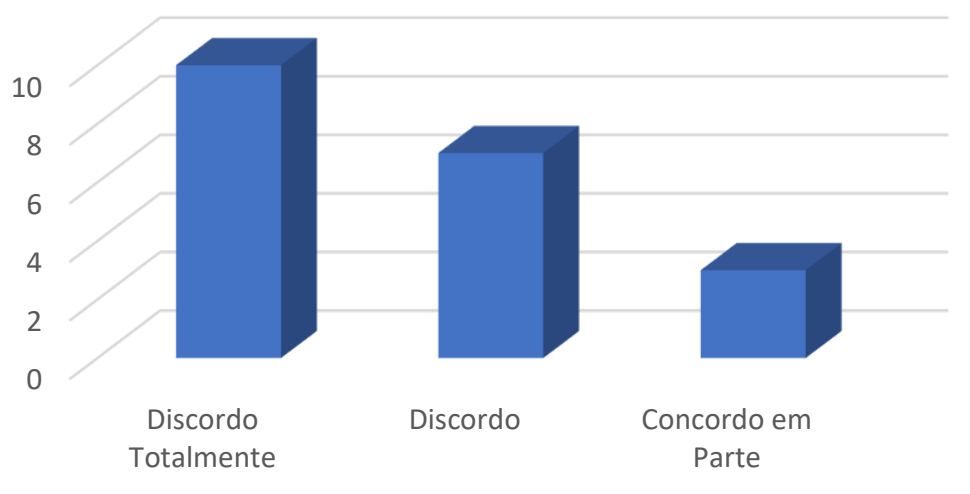

Fonte: Dados da Pesquisa 2018.

De acordo com o gráfico 11, percebe- se que os maiores números de participantes responderam que "discordam totalmente" referente ao estar de mau humor por se sentir isolado no trabalho, pois evidencia que a situação mencionada não faz parte em grande parte do dia- adia dos colaboradores, pois segundo Zanelli (2010) o esgotamento físico e emocional é um processo progressivo ao estresse, que foi constatado visivelmente por condições do trabalho que abala o indivíduo em qualquer ambiente organizacional evidenciando a dimensão psicossocial e favorecendo no processo de adoecimento.

Gráfico 12: A forma como as tarefas são distribuídas em minha área me deixa nervoso

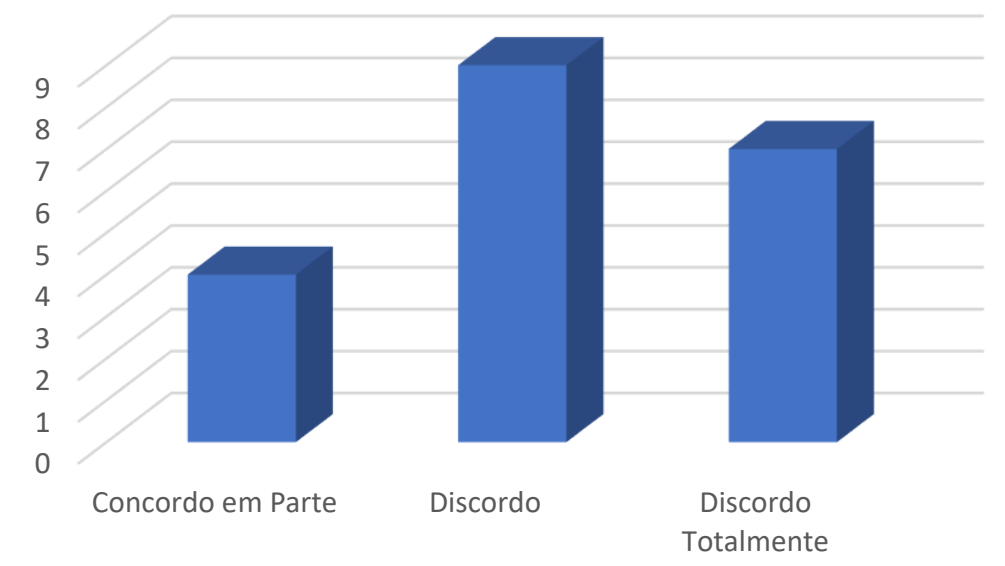

Fonte: Dados da Pesquisa 2018. 
No gráfico 12, que diz respeito de como as tarefas são distribuídas se a mesma causa nervosismo, grande parte dos respondentes afirmaram que "discordam", pois, perante as respostas obtidas isso consequentemente resulta no bom desempenho do colaborador tanto na vida pessoal, como na profissional, pois caso contrário segundo Coutinho e Santos (2010) todas as situações vivenciadas pelos trabalhadores, pode levá-los a apresentar os seguintes sintomas: insegurança na tomada de decisões, consumos exagerados provenientes a ocasionar problemas digestivos, tensão muscular, sendo assim ocasionando problemas na saúde física e/ou emocional com alterações de conduta no trabalho e em casa.

Gráfico 13: Sinto-me irritado com a deficiência na divulgação de informações sobre Decisões do serviço

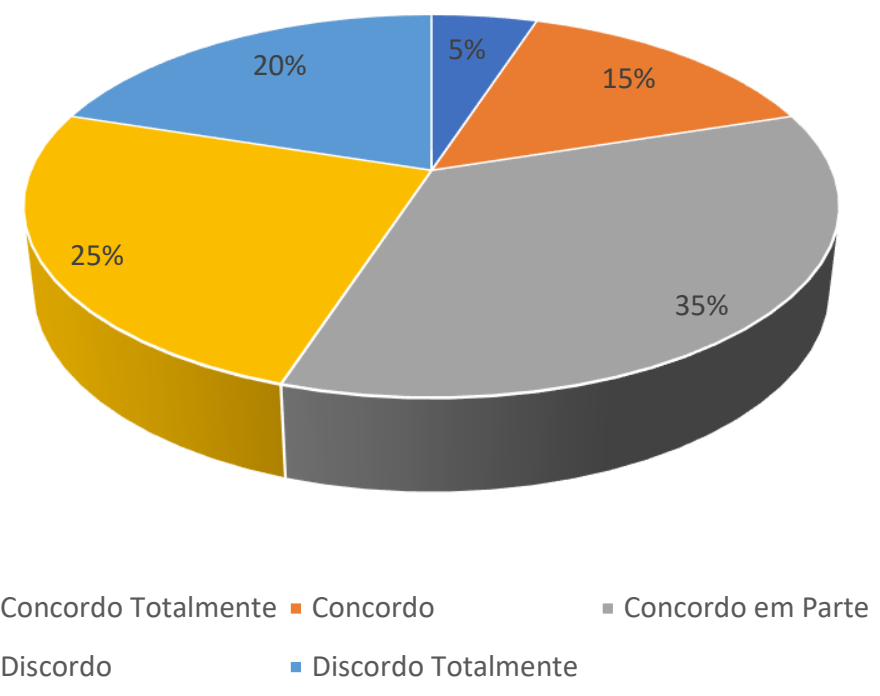

Fonte: Dados da Pesquisa 2018.

A convivência social e o rendimento nas atividades do dia-a-dia ficam comprometidos quando o nível de qualidade de vida é baixo. De acordo com a pesquisa e perceptível no gráfico 13 acima, que 35\% dos respondentes afirmaram que "concordam em parte" a respeito da irritabilidade causada pela falta de divulgação das informações sobre decisões do serviço, perante essa afirmativa Ferreira (2017) relata que diante de algumas insatisfações oriundas do trabalho pode levar ao absenteísmo, e trazer várias doenças, como: problemas no coração, 
estresse, pressão e ulceras, devido à pressão do ambiente de trabalho podendo assim acarretar elevados gastos com assistência medica nas empresas.

Gráfico 14: A falta de autonomia na execução do meu trabalho tem sido desgastante

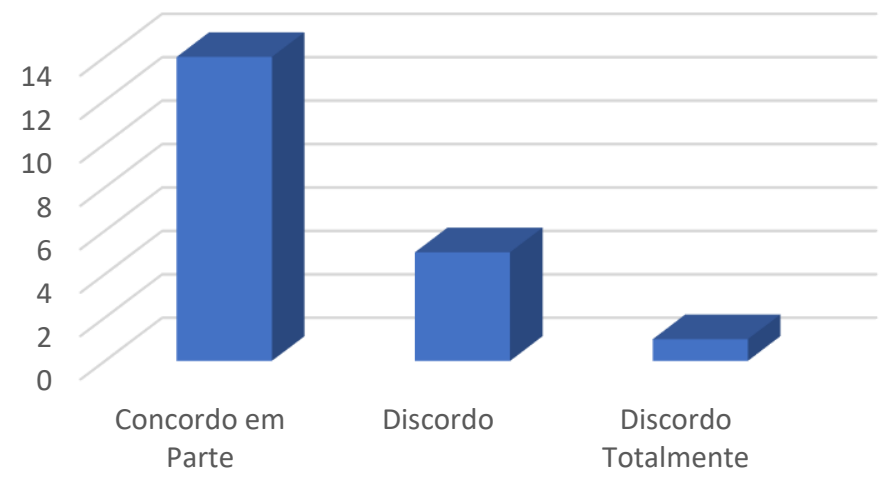

Fonte: Dados da Pesquisa 2018.

A saúde não é considerada apenas ausência de enfermidades, mas sim um estado de bem-estar físico, mental e social. No entanto, o gráfico 14, acima refere a falta de autonomia na execução de atividades e se a mesma é desgastante, que segundo os entrevistados grande parte afirmou que "concordam em parte" compreende-se que é de extrema importância que as informações necessárias para o desenvolvimento das funções estejam claras a todos os indivíduos da organização. Caso contrário, o desenvolvimento e rendimento dos mesmos ficam comprometidos, visto que não se sabe como agir em determinadas situações.

\section{Resultado Textual}

Percebeu-se que, dentre todos os fatores avaliados e apontados pelo artigo, que a suposição de que os desencadeadores do estresse teriam influência sobre colaborador dentro da organização, sendo visto e comprovado diante dos resultados obtidos a inexistência da presença do estresse ocupacional na organização. 
Esperava-se que a rotina de trabalho pudesse ter alguma relação com a percepção do estresse ocupacional.

Ainda, em consideração a todos esses aspectos, levanta-se a importância de haver estudos mais aprofundados a frente ao tema abordado com o objetivo de discutir formas de identificar precocemente os fatores potenciais que auxiliam no desenvolvimento do estresse ocupacional, sugerir e levantar as medidas preventivas para o controle da doença e de modo a garantir a saúde física e mental, bem como a segurança e a qualidade de vida dos profissionais , evitando assim eventuais transtornos frente ao trabalho desenvolvido em sua instituição atuante. Por fim, com realização desse estudo, almeja-se contribuir com a literatura sobre o tema dissertado, como também colaborar em despertar o interesse dos profissionais para construção de novos trabalhos científicos que aprofundem a discussão da temática aqui abordada.

\section{Considerações Finais}

Na esfera da rotina de trabalho do homem moderno, oferecer segurança e saúde ao trabalhador como meta institucional prioritária, significa reconhecer o direito a um estilo de vida saudável, ao mesmo tempo em que se criam condições adequadas para o trabalho na organização.

Nessa situação, produtividade vai além da ideia de uma boa produção ou de ser

competente. É necessária uma junção com a melhoria de Qualidade de Vida, de cada indivíduo no trabalho e suas consequências fora desse ambiente. A melhoria do trabalho significa motivação, compostura e participação no processo de trabalho da organização. Portanto, produtividade significa desenvolver indivíduos, cujas vidas podem ser produtivas no sentido extenso.

Logo, o investimento no capital humano traz um bom resultado em termos de qualidade e produtividade da empresa, pois o equilíbrio físico e emocional das pessoas é sinônimo do crescimento organizacional.

Faz-se necessário que ocorra a prática de um plano para garantir a qualidade de vida do colaborador e este faça parte do plano estratégico da empresa. É de suma importância, o plano 
de carreira para que haja motivação constante dos indivíduos e uma perspectiva de crescimento que resultará no maior rendimento para a empresa. Melhor do que vestir a camisa pela empresa é ter nela um ambiente saudável, no qual todos se sintam bem e felizes por desempenhar suas atividades.

Os resultados desta pesquisa podem servir de subsídio para melhorar a qualidade de vida no trabalho. A identificação dos estressores pode proporcionar ações para relaciona estratégias de enfrentamento eficazes para lidar com o estresse no trabalho, com resultados no desempenho, na saúde e na qualidade de vida.

\section{Referências}

ALVES, E.F. Programas e ações em qualidade de vida no trabalho: possibilidades e limites das organizações. Revista eletrônica FAFIT/FACIC, Itararé/SP, vl. 02, n.1, p.14-25, jun/2011. Disponível em: <http://www.fafit.com.br> Acesso em: 04 set. 2018.

ANDRADE, M. M. Introdução à metodologia do trabalho cientifico: elaboração de trabalhos na graduação. 10 ed. São Paulo: Atlas, 2010.

BARROS, D. M; FUNKE, G; LOURENÇO, R. B. Instituto Bem-Estar: 49 perguntas sobre o estresse. São Paulo: Manole, 2017.

BARSANO, P. R.; BARBOSA, R.P. Controle de riscos: prevenção de acidentes no ambiente ocupacional. 1 Ed. São Paulo: Érica, 2014.

BERGAMINE, C.W. Motivação nas organizações: nem todos fazem as mesmas coisas pelas mesmas razões. 7 Ed. São Paulo: Atlas, 2018.

CRESWELL, J.W.,Projeto de Pesquisa: Métodos Qualitativo, Quantitativo e Misto. Porto Alegre: Artmed. 2010.

CHIRMICI, A; OLIVEIRA, E. A. R. Introdução a segurança e saúde no trabalho. 1 ed. Rio de janeiro: Guanabara Koogan, 2016.

COUTINHO, D. A.; SANTOS, J.W. O estresse no mundo do trabalho: Uma abordagem individual e organizacional. Revista Cientifica Eletrônica de Psicologia, Garça/SP, ano VIII, n. 14, mai/jun.2010. Disponível em: http://www.revista.inf.br. Acesso em: 30 set. 2018.

DUTRA, J. S. Gestão de pessoas: modelo, processos, tendências e perspectivas. São Paulo: 2 Ed. Atlas, 2016.

FERREIRA, P. Í. Clima organizacional e qualidade de vida no trabalho. Rio de Janeiro: LTC,2017. 
FIORELLI, J. O. Psicologia para administradores: razão e emoção no comportamento organizacional. 10 ed. São Paulo: Atlas, 2018.

FRANÇA, A. L. Qualidade de vida no trabalho - QVT: conceitos e práticas nas empresas da sociedade pós-industrial, 2 Ed. Atlas, 2012.

FRANÇA, A. C. L. Psicologia do Trabalho: Psicossomática, Valores e práticas Organizacionais. São Paulo: saraiva, 2008.

GIL, A. C. Como elaborar projetos de pesquisa. 5 ed. São Paulo: Atlas, 2010.

GONÇALVES, C. A; MEIRELLES, A. M. Projetos e relatórios de pesquisa em administração. São Paulo: Atlas, 2004.

KANAANE, R. Comportamento humano nas organizações: o homem rumo ao século XXI. 2 ed. São Paulo: Atlas,2012.

LACOMBE, F. J. M. Recursos humanos: princípios e tendências. São Paulo: Saraiva, 2005.

LAKATOS, E. M; MARCONI, M. Metodologia científica. São Paulo 6 Ed. Atlas 2011.

MAXIMIANO, A. C. A. Introdução à Administração. 8 ed. São Paulo: Atlas, 2011.

MOGAN, G. Imagens da Organização. 2 ed. São Paulo: Atlas, 2002.

ROBBINS, S. P. Fundamentos do comportamento organizacional. 8 ed. São Paulo: Pearson Prentice Hall, 2009.

ROSSI, Ana Maria; PERREWÉ, Pámela L.; SAUTER, Steven L. Org, et. al., Stress e Qualidade de Vida no Trabalho. Perspectiva Atuais da Saúde Ocupacional. 2. ed. São Paulo: Editora Atlas, 2007. 192 p.

SILVA, Flávia P. P.; Burnout: Um Desafio à Saúde do Trabalhador. Revista de Psicologia

SIQUEIRA, M. M. M. Novas medidas do comportamento organizacional: Ferramentas de Diagnostico e de Gestão. São Paulo: Artmed, 2014.

ZANELLI, J. C. Estresse nas organizações de trabalho: compreensão e intervenção baseados em evidencias. Porto Alegre: Artmed, 2010.

ZANELLI, J. C; BORGES-ANDRADE, J. E; BASTOS, A. V. B. Psicologia, Organizações e Trabalho no Brasil. 2 Ed. Porto Alegre: Artmed, 2014.

\section{Como citar este artigo (Formato ABNT):}

ALVES, Lecia Pereira Alves; LIMA, Márcia Maria Leite. Estresse Ocupacional: Uma análise sobre causas, consequências e prevenções em uma clínica médica na cidade de Juazeiro do Norte-CE. Id on Line Rev.Mult. Psic., 2018, vol.12, n.42, Supl. 1, p. 85-108. ISSN: 1981-1179.

Recebido: 29/10/2018;

Aceito: 03/11/2018 